\title{
Raymond Pettibon: Return to Disorder and Disfiguration
}

\section{Citation}

Buchloh, Benjamin H. D. 2000. Raymond Pettibon: Return to disorder and disfiguration. October 92 (Spring): 37-51.

\section{Published Version}

http://dx.doi.org/10.2307/779232

\section{Permanent link}

http://nrs.harvard.edu/urn-3:HUL.InstRepos:3205618

\section{Terms of Use}

This article was downloaded from Harvard University's DASH repository, and is made available under the terms and conditions applicable to Other Posted Material, as set forth at http:// nrs.harvard.edu/urn-3:HUL.InstRepos:dash.current.terms-of-use\#LAA

\section{Share Your Story}

The Harvard community has made this article openly available.

Please share how this access benefits you. Submit a story.

Accessibility 


\section{Raymond Pettibon: Return to Disorder and Disfiguration}

\section{BENJAMIN H. D. BUCHLOH}

... bespeaking the spirit of opposition and revolt, dandies represent what is best about human pride, this need, all too rare among people today, to fight and destroy triviality....

In these troubled periods, certain men-declassed, disgusted, out of work but rich in native strength-can come up with the idea of founding a new aristocracy, all the more difficult to break since it will be based on the most precious and indestructible faculties as well as on heaven-sent gifts that work and money cannot obtain.

-Charles Baudelaire, The Painter of Modern Life

At the moment of the 1980 s when the collective desire to acquire linguistic competence was increasingly and aggressively shifted to an enforced simulation of technological competence, the parameters of the production of visual culture changed dramatically. With this shift toward a myth of self-constitution within the containment of advanced forms of techno-scientific operating systems, even a residual legitimacy of enlightenment aspirations in cultural production seemed to have disappeared. Since the 1960s, these aspirations have defined artistic practices and cultural sites with renewed vigor as emancipatory spaces where the dialectics of subjective imaginary and social symbolic could be productively contested and alternate, future relations could be rehearsed.

The neo-futuristic myth of innovative forms of communication, of a technological progress undreamt of by any prior generation within advanced industrialized capitalism, delivered a universally governing techno-scientific pseudo-competence as the substitute for a linguistic constitution of the self. By collapsing each and every act of linguistic articulation within pre-established formulaic systems that exerted total control and were inexorably linked with ever-more-totalizing demands of consumption, these systems of control seemingly foreclosed the validity of all other cultural conventions. At the same time they eroded the legitimacy, if not the credibility, of those practices and cultural institutions in which the dialectic 


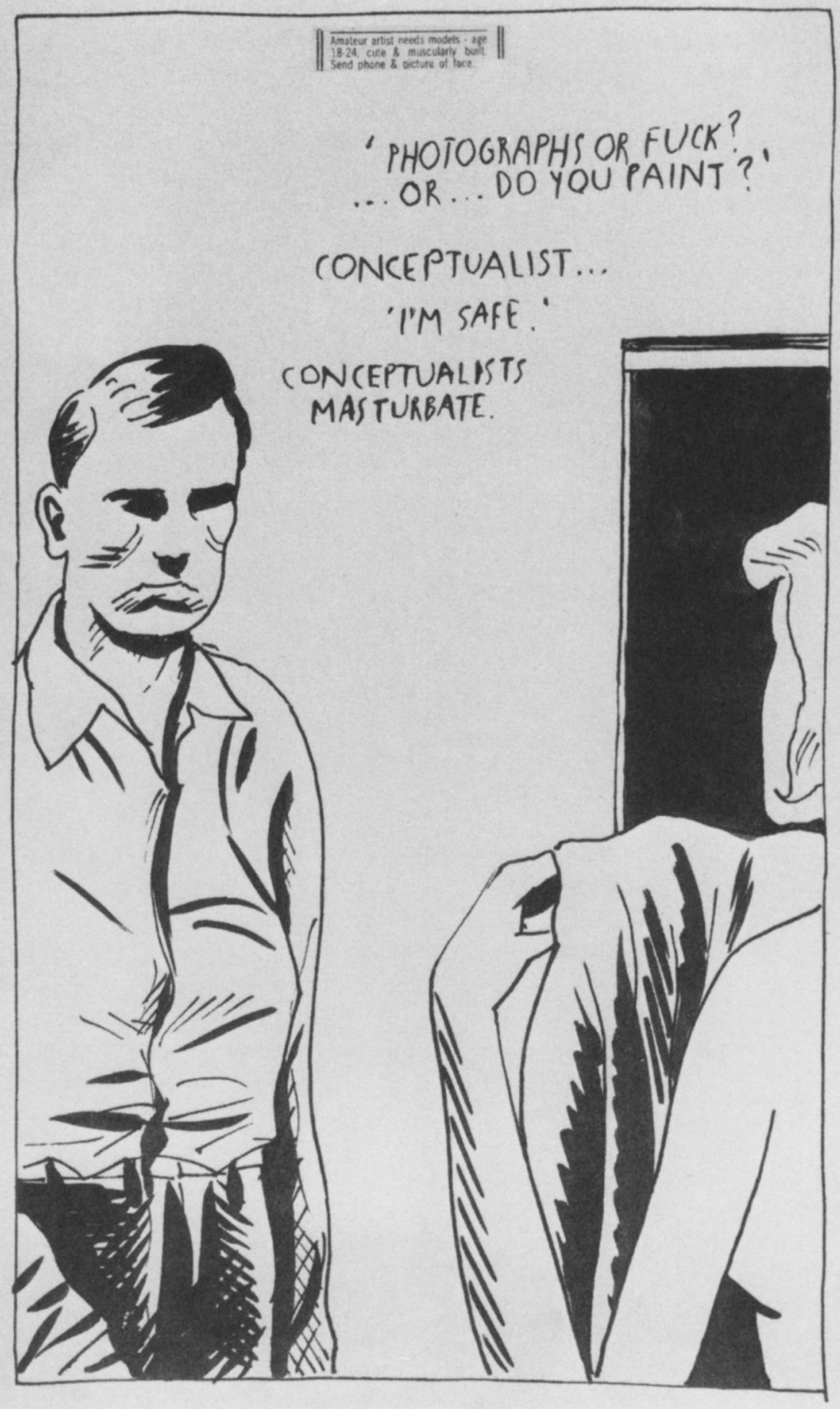


between the imaginary and the symbolic, unfolding as the constitution of identity between the subjective and the social, had been traditionally staged.

In earlier moments of modernity, in analogously constructed instances of crisis between the ever-expanding ideological apparatus of techno-scientific domination and the ever-receding legitimacy of the ideological apparatus of avant-garde oppositional culture, one response-as indicated above in Baudelaire's notorious remark on the topic-had been to emphasize the return to an antidemocratic, if not outright aristocratic and anti-industrial aesthetic, in order to oppose the seemingly irreversible elimination of subjectivity under the conditions of advancing industrialization and democratization.

Inevitably, that position not only renewed emphasis on artisanal skills and the virtuosity of competence to assert the disciplinary boundaries between artistic and techno-scientific forms of knowledge, but its claims for the separateness of aesthetic experience had consequences for its conception of artistic roles and audiences as well. In almost all instances this renewed separateness of the aesthetic defined itself in a return to (neo) classical traditions and neo-figurative conventions of painting and drawing, defying first of all the modernist credo of deskilling. That credo had been proven to be increasingly necessary and exclusively valid in order to achieve actual forms of a new egalitarian communicative culture (this would become evident, for example, in the dominance of the post-cubist aesthetic of the readymade and the photograph).

But antimodernism not only emphasized the renewal of skills as integral to the very essence of the aesthetic, it also countered the prohibitions pronounced by modernism on figuration, narrative, and the mnemonic dimensions of representation. Lastly, in almost all instances, it associated itself-as though there were an inescapable nexus-with a spectrum of political and ideological forms of conservative, reactionary, if not outright fascist responses to the ever-increasing schism between advanced industrial practices of identity formation and the cultural attempts to oppose their false universality by an aggressive retreat into esoteric forms of privileged knowledge.

It is important to recognize that reactionary antimodernism had foregrounded almost without exception the grandeur of those traditions of national and regional culture that had prevailed prior to the arrival of industrialization and democracy. And we encounter only in rare instances, most eminently in the work of Francis Picabia from the late 1920s onward, rabid antimodernism being inscribed into the photography-derived imagery of debased industrial mass culture, pornography, and advertisement.

The return to narrative and figuration, the retrieval of iconic representation by an incessant and ever-expanding deployment of draughtsmanship, have been aggressively pursued in Raymond Pettibon's work since the 1980s when he developed his earliest work, done as "mere" illustrations for a student newspaper at Berkeley, to be followed by the formation of his zine culture project begun with the series The Tripping Corpse in 1981. Pettibon's drawings-mostly pen and ink, graphite, 
occasionally watercolor and crayon combined-shift, often even within one and the same work, between starkly different practices and types of drawing. At one moment, they seem to have suddenly awoken from drawing's near extinction to resuscitate its most hallowed traditions (the chiaroscuro, the expressive graphic gesture, and the dramatic figure) to reach uncanny appearances of virtuosity. Yet at another, often within inches inside the same drawing, technical mastery withers away only to be replaced by a mere haphazard execution reminiscent of Warhol that seems to consider the self-conscious deskilling of drawing at best a dubious camp value. Or going all the way to the opposite end of the spectrum, Pettibon's drawing lapses back into a mechanically produced matrix (cinematic angles of vision, melodramatic close-up views, the comic strip repertoire of stark planar contrasts) as though his drawing had to be contained within the perceptual and cognitive coma of mass culture, appearing deeper and darker in Pettibon's work than any other simulated before by Pop art.

At the same time that the work engages with a rather broad and contradictory range of drawing modes, it stages the reappearance of language performances within the field of the visual representation (enunciations, captions, quotations, pronouncements). Unlike their artistic predecessors in the context of Conceptual art, these statements foreground narrative, the literary and the poetological, if not the outright poetical itself. A major precursor, if there is any, for Pettibon's approach to incorporating the simultaneously available modes of speech and writing into a visual work, pronounced as it were from a heightened form of theoretical linguistic awareness, could be the post-Conceptual work of Jenny Holzer. Pettibon, like Holzer, adheres strictly to a nonjudging and nonselective arrangement of quotations of the language performances and ideological subject positions inhabited in everyday speech, thus making it impossible for the viewer/reader to detect a centralized speaking and judging subject and necessitating a continuous revision of the reader's own responses to the positions performed in the text.

In Pettibon's drawings and writings, these invocations of the multiplicity of historically available linguistic functions are as frequently inscribed within the languages of the everyday (i.e., a rabid rhetoric of sexist masculinity, forms of psychological debasement and social deviance and violence in its prefabricated mass-cultural mediation, the deranged utterances of the ideologies of the political and religious right) as they originate in a vast mnemonic compendium of literary citations.

When Pettibon's inscriptions draw on these resources of an apparently universal literary memory they seem to quote-in secret affinity-especially from those writers that had faced the conflicts between industrialization and spirituality earlier, ranging from the work of William Blake and John Ruskin to Henry James and James Joyce. Presenting the myriad citations from the world of canonic literature not only effortlessly but with an apparent conviction in their immediate accessibility and applicability in the present makes their juxtaposition with the 


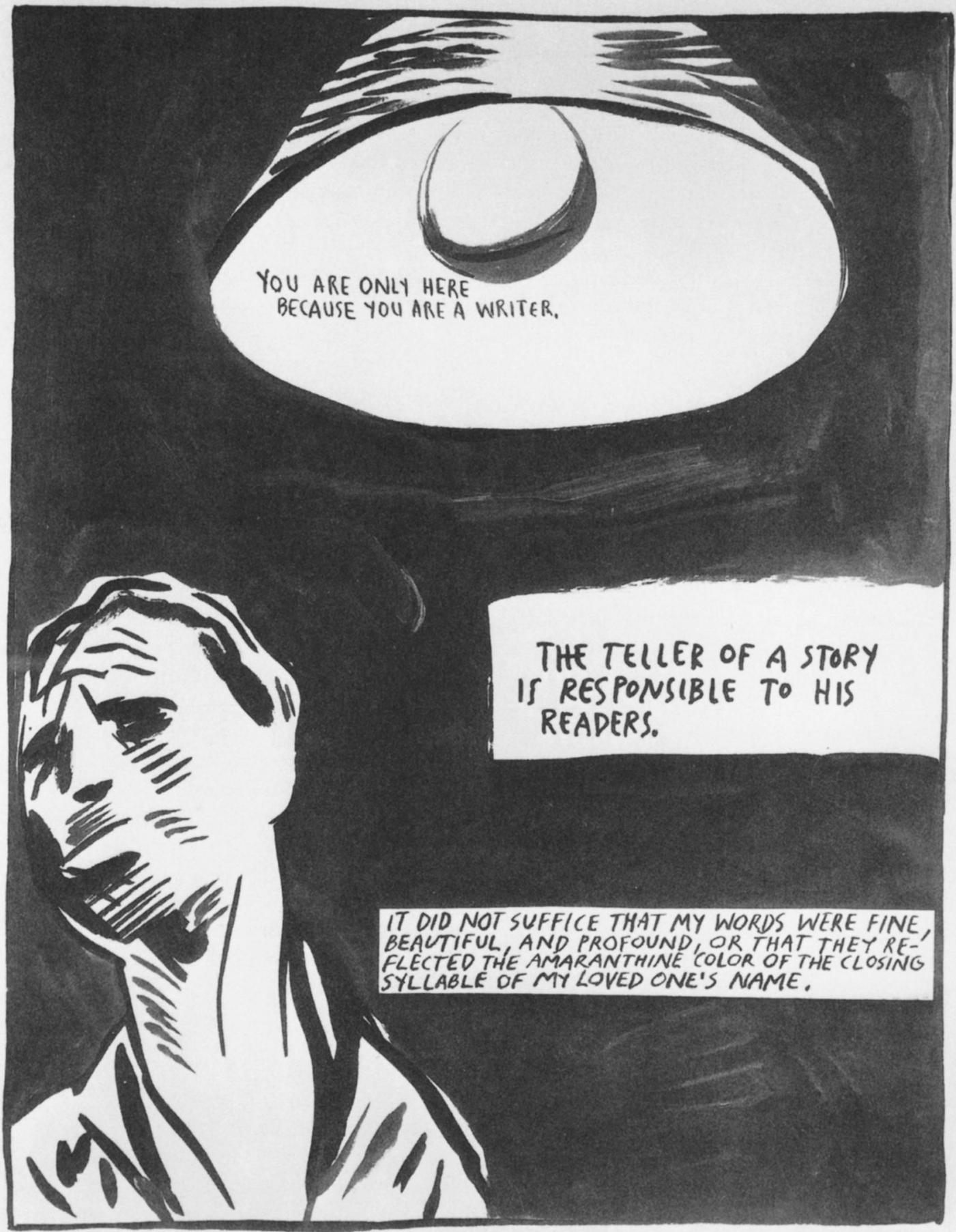

Untitled. 1987. 
quotations from the brute and decrepit speech of everyday illiteracy a source of continuous bewilderment for the reader/spectator.

Pettibon's writings/drawings thus not only violate the typical post-1960s assumptions (established since Minimalism and Conceptualism in particular) that artistic practices based on abstraction and linguistic definitions would automatically position themselves within progressivist enlightenment perspectives, but more importantly, perhaps, his work denounces the foregone conclusion that in order to achieve a socially progressive, radical aesthetic, avant-garde activities had to maintain modernism's mimetic relationship to the governing techno-scientistic imaginary and therefore would have to spurn any contact, let alone any continuity, between visual culture and the complexity of conceptual and cognitive models from the literary imaginary (e.g., narrative, figuration, mnemonic representation) upon which cultural practices had traditionally drawn.

This peculiar synthesis of traditionalist and mechanical drawing, literary memory and mass-cultural languages (before we even look further into the subject matter and iconography of Pettibon's historical pandemonium) suggests that we consider his work at least potentially partaking in a reactionary aesthetic of anti-modernist returns. After all, it re-establishes precisely those conventions of figuration and narration that abstract art and, more recently, Minimalism and Conceptualism had claimed to have transcended in the 1960s and '70s.

Initial responses to the work might also suggest that, in its apparent identification with the most debased forms of the rhetoric and behavioral patterns of anomic social and subjective existence, Pettibon (like Picabia before him) now introduces with a cynical vengeance the very desublimatory erosion within the sphere of cultural production that mass-cultural aggression and social enforcement of anti-enlightenment politics already maintain and continuously expand in the sphere of everyday life.

To counter such misreadings, we will consider first of all the distribution form of Pettibon's drawings and how they can be situated with regard to the functions and morphology of drawing in the sphere of avant-garde culture. The sheer quantity-one could almost say, the industrial scale-of Pettibon's production of the last fifteen years (numbering probably in the low ten thousands if one counts the work for his zine publications, as one should) dissociates his work-in spite of its astonishing skirmishes with skill, narrative, expression, and the selfreflexive grapheme-from both traditionalist figurative drawing and the graphic conventions of modernism, and situates it within the order of industry. One should be careful, however, not to identify that order of industrial production solely with Pettibon's iconography and style of execution, even though the drawings situate themselves clearly within mass-cultural patterns: their graphic matrices are the comic strip, the film image, and the incessant flow of television imagery-all of which, it should be stressed, have served and continue to serve as the actual resources of Pettibon's artistic project.

Yet it seems that Pettibon also relates to an entirely different industrial 
dimension in that he retrieves those moments of mass-cultural modernity before the epistemic devalorization of drawing's functions as "mere" illustration would occur. Thus, some of the most important draughtsmen in Pettibon's artistic development were those of the early to mid-nineteenth century, in particular Blake, Goya, and Daumier. Their paradigmatic importance for Pettibon seems to have derived not just from their extraordinary competence as draughtsmen, but equally from their commitment to a type of drawing that could be defined as both communicative and reproducible. Spurred by their early recognition of the impact and options offered by the new technologies of reproduction and mass-cultural distribution (e.g., the lithograph, the illustrated press), they renewed a commitment to what had been the populist dimensions of the graphic arts (e.g., the medieval and early Renaissance woodcut) and drawing's communicative and populist potential, its anecdotal or moralistic narrative, were now once again conveyed by didactic inscriptions, captions, or the performance of dialogue.

Of course Pettibon's project is not historically naive, sentimentally attempting to reconstruct a moment of popular culture and resuscitate the conditions of early industrial illustration; not actually believing in the historical possibility of re-establishing those expressly communicative modes of address to specific audiences and the particular forms of distribution that had facilitated such a project in the nineteenth century. Yet one should neither simply disregard the degree of specificity of audience address that Pettibon developed in his earlier work, distinctly oblivious of potential art-historical references as much as of potential art world audiences, when he operated not only as the draughtsman and designer, but also as the publisher and distributor of his zine project, which was offered largely to the ruins and revivals of a California music and drug culture derived from the 1960s and revised in the $1980 \mathrm{~s}$.

The harsh and clumsy drawing style of Pettibon's early zines actually does not allow one to distinguish easily whether these remain deliberately close to the drawing culture of underground magazines as a result of a virtuoso performance of false naiveté, whether drawing skills and artistic knowledge are displaced here by a gesture of solidarity with the compulsive crudeness and the instrumental emergency with which zine drawings are driven to communicate with their marginalized and self-marginalizing audiences, or whether Pettibon's drawings only acquire their astonishing intensity and art-historical and technical mastery in the course of his subsequent development as an artist, gradually moving away from the aspiration for a direct subcultural communication with the members of his presumed audience of post-Altamont sex-drugs-and-rock-and-roll consumers.

Yet again, it would be equally erroneous to sentimentalize Pettibon's production in terms of a subcultural identity alone. Rather, it seems obvious that his endeavors, even in the initial stages of the zine project, are artistic as much as they are subcultural (as difficult as it might have become to disentangle these two spheres, since it is of course one of the central questions posed by Pettibon's work whether it would seem any longer possible or even desirable to maintain such a distinction). 
While the erasure and hybridization of these traditional disciplinary boundaries between avant-garde discourses and subcultures had been constitutive of avant-garde practices throughout the twentieth century, this deliberate collapse of the differences remained in all but a few instances on the level of mere simulation. These crossovers, however, have in fact become intensified since the rise of Warhol's project to both the status of a paradigm and to the status of an entrepreneurial empire. One of the last instances of such a systematic crossover occurred in the context of Conceptual art and its combination of textual and photographic materials and their corresponding distribution forms in either magazine publications or the cheaply produced book. A comparison of Pettibon's zines with these works (e.g., the books of Ed Ruscha or the writings of Lawrence Weiner) would certainly give us evidence of Pettibon's radical departure from these models. The zines drawn by and published by Pettibon are in fact not any longer engaged in a somewhat numinous project of merely altering the object status of the work of art, neither do they originate in the desire, typical of the artists of the $1960 \mathrm{~s}$, to alter and expand audiences abstractly. Rather, they are conceived with a very specifically chosen audience in mind and they want to establish a communicative, if somewhat clandestine and exclusionary relationship with that audience (as is typical of all subcultural forms of communication).

Drawing in Pettibon's work thus operates between two crucial moments of the formation of mass culture: the first one is that of its beginnings in the initial decades of the nineteenth century when avant-garde practices had to define themselves increasingly in opposition to and secession from mass culture and had to desist from pursuing their initial project of serving the audiences of the newly industrialized democracies. The second one is that of the end of avant-gardist opposition to mass culture at the conclusion of the twentieth century, once avantgarde practices themselves have become fully incorporated within culture industries and have become manifestly obsolete with regard to the overpowering technologies of mass-cultural production that have all but completed their project of total control.

Pettibon's work responds to the first moment with an archaeological recovery of the legacies of drawing as illustration, caricature, and populist communication, while it responds to the second, the apex of contemporary mass-cultural image production in its most advanced technological forms, by taking these forms as the inescapable matrix of his practice: to contain his return to traditionalist artisanal and individualist expressive drawings as much as to contain their iconography. Yet, most importantly it seems, the mass-cultural matrix determines the iterative structure of Pettibon's drawings, effecting the continuous devalorization of their status as unique fabrications by sheer quantity, as though the incessant drive of masscultural image production had set the breakneck pace and the pulse of his artistic output as well.

Looking back unto the work of Daumier and Goya from the perspective of the comic, the filmic narrative, and the television serial, Pettibon's work makes 
evident first of all to what degree the psychic spaces of subjective and social interaction were still presumed to be at least partially transparent and accessible to representation in the caricature and the illustrations of early industrial mass culture.

Pettibon's archaeology of those forms reveals furthermore to what extent those representations of the social and the subjective have themselves become literally and metaphorically flattened to the degree of extinction in their transition from caricature and illustration in the nineteenth century to a fully industrialized cartoon and comic-strip culture in the twentieth. If Daumier's realism could still lay claim to a degree of differentiation and particularity in the physiognomic depictions of his characters (both those of class and of subjective identity), it is precisely the particular's total disappearance that corresponds to the overall scission of the psychic space of the subject from the social field of mass-cultural representation. In hindsight, the concomitant rise of modernism's flattening of all pictorial depictions only seems to be the logical correspondence to that elimination of the social and the subjective from the field of representation altogether. After all, it was only toward the second half of the nineteenth century, with the first crisis of realism's aspirations and the subsequent rise of a theory and ideology of modernism, that drawing's narrative and communicative functions were replaced by an increasing focus on (and eventually exclusive valorization of) its expressive, notational, and self-referential dimensions.

Since then, we have been confronted for quite a while with drawing practices, especially those under the impact of automatism, that have dismantled the traditional assumption of drawing as being either an illustrational narrative, a functional, preparatory sketch or study, or a fully executed, self-contained representation. These epistemes of drawing were replaced-at least since Surrealism, if not sooner-by a variety of new, often incompatible definitions of drawing as the record of an infinity of structurally or psychically equivalent events, destabilizing and finally displacing all traditional assumptions about drawing as the record of an exceptionally condensed moment of experience. Drawing could now function either as an instantiation of a pure spatio-temporal process (e.g., the line from Pollock to Serra) or it could pretend to be the mere trace of a neuro-motoric and physiological/libidinal performance (e.g., the line from Michaux to Twombly), or drawing could take on the guise of a merely functional notation (the line from Duchamp to Johns to Sol LeWitt). What these otherwise incompatible models shared, under the impact of automatism and deskilling, was the claim that drawing could be defined at the most by a seemingly endless iterability, as an open and interminable activity, ultimately unqualifiable in aesthetic terms.

As we have already argued, the apparent infinity and incessant articulation of Pettibon's drawings seem to derive primarily from a different order altogether, not that of psychic automatism and the serialization of the iterable psychosexual impulse but from the external demands and restraints of industrial image production. Or, perhaps one should recognize instantly that one of the links established in Pettibon's drawings between the public sphere of industrial production and the 
AND HIDDEN BEHIND THE SINUOUS FOLDS OF A SILK (URTAIN:

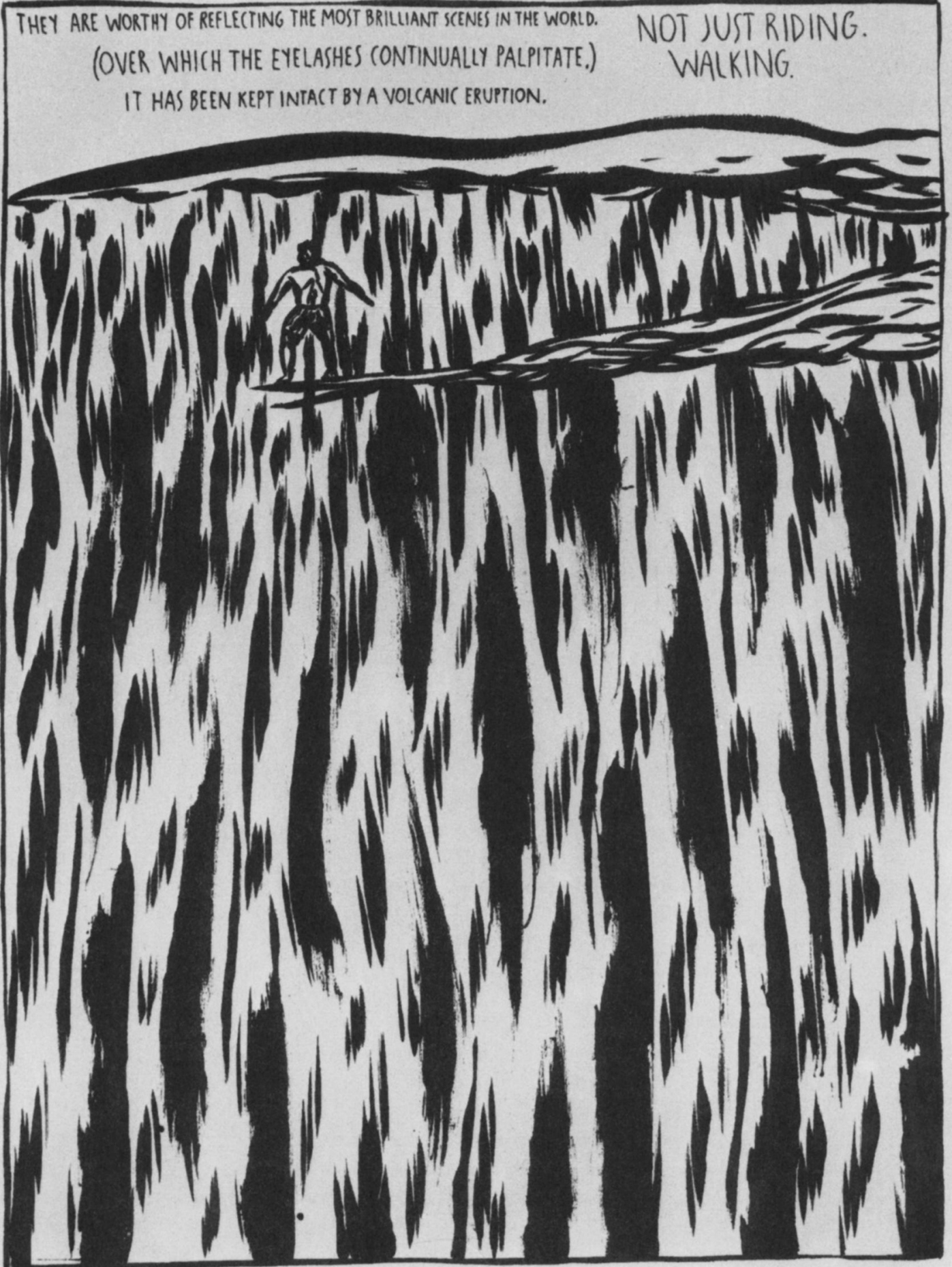


private sphere of psychosexual impulses is precisely the insight that the domain of the libidinal (its roving and raging textures and graphemes) can neither be perceived nor designed any longer as operative outside of a pre-established, industrially produced behavioral and psychosexual matrix.

Thus, the actual graphic and scriptural execution of Pettibon's drawings, what one would have traditionally identified as their "style," can hardly be separated from the compelling range of their iconographic invention. But if one succeeded for a moment in splitting the two integral elements of his work, one would discover that Pettibon has in fact achieved a project that seemed heretofore inconceivable: namely to synthesize the model of drawing as pure matrix (embodied in Johns) with the model of drawing as pure grapheme (embodied in Twombly). If the first had insisted on the concealment of the subjective impulse and had denied the gestural trace any privileged access to function as an index of subjective experience, then the latter had precisely foregrounded the pure indexicality of the grapheme as subjective inscription in order to reveal to what extent the formation of subjectivity originated in the commonality of neuro-motoric and psychosexual impulses. This dialectic would at least partially explain why drawing in Johns and Twombly in the late 1950s only generated the semblance of an opposition when in fact both artists were profoundly linked by the actual complementarity of their projects: to rearticulate drawing after Surrealist automatism, and, simultaneously, Freudian concepts of the unconscious, had become profoundly problematical.

One of the most astonishing achievements in Pettibon's drawings is, then, to have reformulated this dialectic of matrix and grapheme altogether. The matricicial mode had a tendency to rigidify, to classicize, and thereby to become affirmative, as it had happened after Johns, in particular in the drawings of Lichtenstein and Warhol that-while derived from mass-cultural imagery as matrix-had aspired to become like Matisse yet had in fact more often than not ended up like Cocteau. Pettibon's response is not only directed at the relatively anodyne subject matter of these Pop artists, it is perhaps much more precisely addressing the sinuous elegance and the seemingly imperturbable linearity of their drawings. Against their placid acceptance of the cartooned forms of social interaction and articulation, Pettibon's drawings reinscribe the compulsive, fractured immediacy of the expressive notation made under duress, as if dictated by the urgency of the scenes of crime, violence, and obscenity that they try to come to terms with, as drawings.

At the same time, the purely corporeal grapheme of a draughtsman like Twombly is recharged by Pettibon with a mass-cultural concreteness and circumstantial specificity that purges the corporeal notation even of its last remnants of bodily jouissance, a promise still operative in Twombly's dialectical relationship with automist legacies (in the way that Roland Barthes had seductively celebrated his work). Twombly's drawings had circumscribed a body more fully constituted in the resurrection, rather than in the repression of anal and oral pre-genitality, and they had publicly incorporated those registers of experience into the grapheme and into the field of the representable. 
Pettibon can clearly no longer sustain the aspiration to anchor the grapheme within the phenomenological ground of the liberated sexual body; neither can he sustain the hope to reimbue drawing with the power of rupturing or subverting hierarchical concepts of genitality or heterosexual identity. His drawings deny that sexuality in general and pre-genital perversion in particular could assure their spectators of the accessibility of any anti-bourgeois models of counter-subjectivity. Thereby he undoes once and for all the assumption that drawing can still deliver alternate models of corporeal behavior and of sexual organization, in the manner that the Surrealist traditions, from their rediscovery of de Sade right down to psychic automatism and its liquidation in Twombly's hands, had still promised.

It is not only that Pettibon's graphic inscriptions of sexual deviance and corporeal violence reach deeper into the recesses of the psychosexual apparatus of post-bourgeois anomic subjectivity under late capitalism, but acts of sexual deviation and rebellion appear in Pettibon's iconography-as in Foucault's theorization of sexuality - as always already inextricably bound up with, if not actually implementing, the larger systems of socially exerted domination and control.

At the same time one should note that the abject obscenity of a large number of Pettibon's figures and texts (visually disfigured, textually dislodged, psychically debased), even in the amplitude of cases depicted and quoted, maintains an amazing specificity in tracing those precise intersections between the supposedly private realm of subjectivity and the supposedly public realm of ideological and political belief systems. Individual derangement, the spaces of the family, and the types of social violence and sexual pathology (i.e., the fundamentally private psychic formation of late capitalist society) and the mass-culturally enforced delirium, the narratives of B-movies and television serials (i.e., the ideological state apparatus of the pathological public sphere) appear here as intrinsically connected. These linguistic and psycho-sexual formations of pathology, and the social spheres in which these formations are operative, appear as consistent citations in the four central, reoccurring subjects of Pettibon's narratives.

The first of these could be described as the paradoxical structure of religious delusion appearing in vernacular speech. The peculiar clashes between the two spheres suddenly unveil the actually existing decrepitude of metaphysical desire in the advanced forms of consumer culture and anomic social relations. The second major subject, related to the first, is the continuous account of the aftermath and the wretchedness of the counter-cultures of hippies in the 1960s. Their forms of helpless opposition appear in Pettibon's retroactive reflection as a nightmare in which the consumption of sex, drugs, and rock and roll had been configured as the dialectical counterpart to the society of consumption. While articulated from the perspective of a compassionate, negative solidarity as much as from that of critical bewilderment at the horror of that subculture's naive aspirations, the counterculture of the 1960s appears here as the mere travesty of a radical anarchistic project for a social-political transformation of conditions of everyday life that are governed by pure instrumentalization and economic reproduction. 


\section{HOLY BIBLE.}
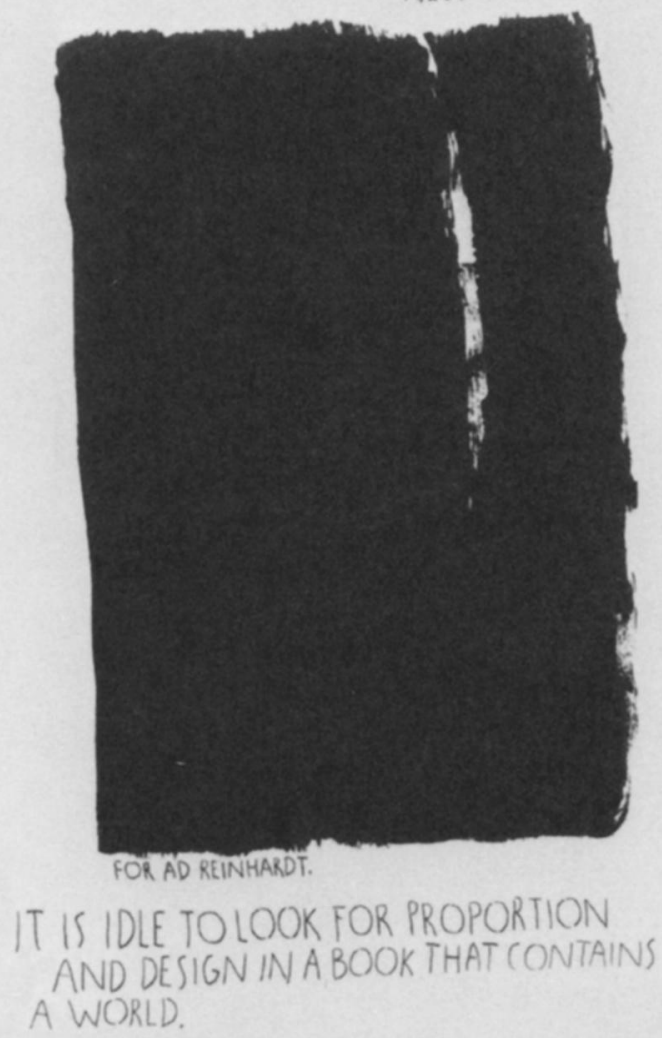

Untitled. 1991. 
The third subject, as was true for the first two as well, had been already central to numerous zine issues drawn and published by Pettibon in the early 1980s. It is the vast pandemonium of sexual disorders, pathologies, phantasmagorias (drug and alcohol addiction, kleptomania, scopic, voyeuristic and exhibitionist compulsions, masculinist forms of sadism, and sexist, often murderous violence, to name but a few) that inhabit Pettibon's figures with the plausible evidence of a socially established norm or normalcy. The last of the four central complexes of Pettibon's iconography shifts from the intimate pathology of private life to its corresponding configurations in the pathological public sphere: the figures imposed for masscultural or political identification. Again, what is most astonishing in these suddenly revealed entwinements of psychic myths and mass-cultural domination is, first of all, the contiguity of the private and the public forms of delusion and debasement.

That is, on the one hand, the revelation to what extent media culture has actually succeeded in generating collective forms of desire and adulation that border on the sheer travesty of religious experience and metaphysical desire: its victims speak, look, and act exactly according to the paths that mass-cultural consumption has prescribed. On the other hand, Pettibon's narratives reveal to what extent the victimizers themselves, the figures of public power, the ideological and political agents of domination (e.g., the Kennedys, Herbert Hoover, and Nancy Reagan as much as the cult figures of media culture from Joan Crawford through Elvis Presley to Charles Manson) are constituted within the same depravity and turpitude that the system they represent actually enforces on a collective level.

But in all instances where the social and ideological configurations of a pathological public sphere manifest themselves in Pettibon's work (or, as one could argue, in those instances where Pettibon gives a realistic account of the disfigured forms in which sexual and metaphysical desire appear under the repressive conditions of a society of control and consumption), a deep ambivalence in the narrative and the depiction prevents us from a simple cathartic distantiation from circumstances that we have supposedly escaped or from which we have been fortunately protected. We are neither attending a moralist's didactic account nor a therapeutic drawing session, since Pettibon's realism is not that of Brecht, in which disidentification is tantamount to seeing an alternate conception of social relations and subject formation. Pettibon's ambivalences derive rather from an identificatory realism (such as Jean Genet's, for example) in the sense that each textual citation and each figurative presentation contains at least an index or an icon that considers depravity as a shared, if not as the last, condition of resistance. And while that ambivalence does not necessarily originate in a positive identification with the figures of speech and the behavior depicted, it certainly generates insight into the degree to which mass culture holds all other forms of transcendental desire, all liberatory metaphysics and emancipatory practices of thought, in utter contempt in the present.

Thus even Pettibon's most venal or banal depictions lead us to the recognition 
that his project is driven by the question of whether any form of desire (aesthetic, political, sexual, or metaphysical) can at all be considered in the present as an articulation of transgression or subversion (or, as T. W. Adorno once suggested, whether one can recognize a society's relationship to Eros by the way that it treats its prostitutes).

One dimension alone, that of the literary imaginary, however fragmented and dispersed, seems to counteract collective oblivion and the obliteration of the subject in Pettibon's drawings. While suffering the same fate of extreme desublimation and dislocation as all other forms of sexual and metaphysical desire in the drawings, the dispersed citations from the literary universe (unidentified, disconnected, decontextualized) operate as the dialectical-opposite of the mass-cultural depravity that governs the anomic world of Pettibon's post-utopian universe.

These "literary" and "poetical" quotations, historically the most specific and the most secularized appearances of metaphysical and sexual desire, operate in Pettibon's work in various oppositional functions. First of all, as the linguistic and poetical countermemory to the mass-cultural effacement of the linguistic constitution of subjectivity, they rupture the apparent homogeneity of the anomic and aphasic totality with sudden epiphanies of voice, tonality, and diction.

Thus the citations, appearing as mnemonic fragments of the poetical, as allegories of the literary rather than the literary itself, make language figure in the drawings as the very embodiment of transcendental desire in its most secularized and once commonly accessible form, however lost it may appear in the present. Against the background of Pettibon's universe of everyday speech, the sudden appearance of these fragmented and dislocated quotations can take on the aweinspiring intensity of the sublime (a pursuit permeating Pettibon's work throughout).

Yet beyond their function as countermemory, the literary quotations also establish a crucial epistemic distantiation from recent artistic practices whose primary focus had been the critical displacement of visuality by the linguistic proposition. Citations in Pettibon's drawings therefore remind the reader that the linguistic can serve as a countermodel to both the mimetic symbiosis that had linked artistic production unconsciously to the techno-scientific imaginary (most recently in Minimalism) and its identification with that imaginary's preferred object, the commodity (most recently in Pop Art). But perhaps more importantly for Pettibon-since Conceptual art constituted the historical horizon against which he developed his project-would be the realization that the linguistic critique of visuality does not have to extend the reign of the techno-scientific even further into the realm of language itself by taking on the guise of the languages of total administration. Or rather, if that proposition might in fact have served as a major stage in the critique of visuality under the auspices of the radical enlightenment aspirations of the 1960s, it is against the inherently repressive structure of this model itself that the memory of the darker underside of the 1960s (e.g., Charles Manson) has to be resuscitated in Pettibon's work. As much as his drawings have 
to rearticulate visuality as the repressed spaces of the mnemonic, in whatever fractured mediation and faceted form it could be mobilized in the present.

Thus the return to figuration and the retrieval of the poetical and the literary in Pettibon's work, rightfully suspected of partaking in a long-established aesthetic of antimodernism, appear in a slightly different perspective: to rescue as a practice of countermemory the mnemonic spaces of language and visual representation under the conditions of their systematic extinction by techno-scientific rationality and spectacle culture. And by situating his counter-enlightenment critique in the deepest recesses of social and psychological abjection, he imbues the ruins of figuration and the records of literary memory with their former promises at precisely those social sites where the resistance against techno-scientistic rule and the results of its most advanced devastation are the most evident. 